\title{
ФИЗИКА
}

УДК 519.7

\section{Особенности массопереноса при ионной имплантации}

\author{
Р.Б. Абылкалькова, Л.И. Квеглис, Б.К. Рахадилов, Г.С. Бектасова
}

Восточно-Казахстанский государственный университет им. С. Аманжолова (Усть-Каменогорск, Казахстан)

\section{Features of Mass Transfer During Ion Implantation}

\author{
R.B. Abylkalykova, L.I. Kveglis, B.K. Rakhadilov, G.S. Bektasova \\ Sarsen Amanzholov East Kazakhstan State University (Ust-Kamenogorsk, \\ Kazakhstan)
}

Исследованы продукты реакции, полученные при ионной имплантации азота, кислорода и фосфора в вольфрамовую мишень. Выяснены условия создания новых соединений при высокодозной имплантации, приводящей к процессам быстрого массопереноса ионов в материал мишени. Установлено, что ионная имплантация азота в вольфрам приводит к возникновению фазы внедрения $\mathrm{W}_{2} \mathrm{~N}$ с ГЦК-структурой; имплантация кислорода - к образованию фазы с плотноупакованной ГЦК-структурой, близкой по структуре и параметрам к W 2 ; фосфора - к образованию фосфида вольфрама $\mathrm{W}_{2} \mathrm{P}$ с орторомбической структурой после дополнительного отжига при температурах, превышающих 800-900 ㄷ․ Сделана оценка локального давления потока ионов на поверхность мишени, которое приводит к локальному искривлению кристаллической решетки, благодаря чему возможен быстрый массоперенос имплантированных ионов в материале мишени.

Образование фаз внедрения при ионной имплантации является результатом локализации сдвиговой деформации в условиях ускоренного массопереноса. В условиях высокодозной ионной имплантации формируются высоконеравновесные пересыщенные твердые растворы, а также высокодефектные структурно-неравновесные состояния с высокой кривизной кристаллической решетки.

Ключевые слова: ионная имплантация, локальное давление, быстрый массоперенос, фазы внедрения.
In this paper, the reaction products obtained by ion implantation of nitrogen, oxygen, and phosphorus into a tungsten target are investigated. The conditions for the creation of new compounds during high-dose implantation, leading to the processes of rapid mass transfer of ions into the target material, have been clarified. It has been established that ion implantation of nitrogen into tungsten leads to the appearance of the interstitial phase of $\mathrm{W}_{2} \mathrm{~N}$ with FCC structure; oxygen implantation - to the formation of a phase with a close-packed structure of the FCC structure, which is similar in structure and parameters to $\mathrm{W}_{2} \mathrm{O}$; phosphorus implantation - to the formation of tungsten phosphide $\mathrm{W}_{2} \mathrm{P}$ with an orthorhombic structure after additional annealing at temperatures exceeding $800-900{ }^{\circ} \mathrm{C}$. An estimation has been made for the local pressure of the ion flux on the target surface which leads to a localized curvature of the crystal lattice due to which rapid mass transfer of implanted ions in the target material is possible.

The formation of interstitial phases during ion implantation is the result of shear deformation localization under conditions of accelerated mass transfer. Highly nonequilibrium supersaturated solid solutions, as well as highly defective structural-nonequilibrium states with a high curvature of the crystal lattice, are formed under conditions of high-dose ion implantation.

Key words: ion implantation, local pressure, fast mass transfer, interstitial phases.

DOI 10.14258/izvasu(2019)4-01 


\section{Введение}

В настоящее время особый интерес вызывают покрытия на тугоплавких металлах, полученные методом ионной имплантации, создание которых представляет научно-практический интерес в широком масштабе. В рамках национальных и международных программ осуществляется проработка инженернотехнологических и технико-экономических проблем демонстрационного термоядерного реактора-токамака. В этих программах формулируются конкретные условия работы элементов реактора и критерии выбора конструкционных материалов. Не случайно тугоплавкие металлы и сплавы на их основе, обладающие наибольшей сопротивляемостью эрозии, температуре и давлению, являются одними из первых кандидатных материалов для элементов термоядерного реактора (диверторных пластин, первой стенки и т.д.). Кроме того, они же обладают оптимальным для условий работы дивертора сочетанием прочностных и теплофизических свойств. Так, оказалось, что вольфрам обладает минимальным коэффициентом распыления и имеет наибольшую прочность в широком интервале температур. Из этого следует, что материалы и сплавы, модифицированные методом имплантационной металлургии, окажутся в числе первых конструкционных материалов, способных работать в экстремальных условиях.

Впервые гипотеза о существовании давления электромагнитного излучения была высказана И. Кеплером в XVII в. для объяснения поведения хвостов комет при пролете их вблизи Солнца. В 1873 г. Максвелл дал теорию давления света в рамках своей классической электродинамики. Экспериментально световое давление впервые исследовал П.Н. Лебедев в 1899 г. Главной сложностью было выделить световое давление на фоне радиометрических и конвективных сил (сил, обусловленных разностью температуры). В условиях ионной имплантации давление, приносимое излучением, исследовали Дж. Мейер, Л. Эриксон, Дж. Дэвис, Е.И. Зорин, П.В. Павлов, Д.И. Тетельбаум, В.С. Вавилов, Х. Риссел, И. Руге, Дж. К. Хирвонен и др. При прохождении каскадов атом-атомных соударений в материале могут возникать высокие давления. Уровень напряжений в имплантированных металлах достигает значений порядка десятков ГПа. Внутренние напряжения приводят к кривизне кристаллической решетки, к образованию фаз высокого давления, фазовым превращениям мартенситного типа и др.

\section{Методика эксперимента}

Имплантация ионов (N, O, P) в образцы тугоплавкого металла - вольфрама проводилась на ускорителе «Везувий 2-450» (ИЯФ НЯЦ РК). В качестве исходного материала использован монокристаллический вольфрам чистотой 99,96\%, вырезанный по плоскости (110) в виде прямоугольников размерами $8 \times 1,5 \times 1$ мм $^{3}$. После механической обработки образцы подверга- лись электрохимической полировке с целью удаления деформированных слоев.

Ионная имплантация азота и кислорода с энергиями 70 и 80 кэВ, а фосфора 150 кэВ соответственно проводилась в вакууме $1,3 \times 10^{-3}$ Па при плотностях тока, не превышающих 1 мкА × $\mathrm{cm}^{-2}$. Дозы имплантации были выбраны следующим образом: $1,87 \times 10^{17}\left(\Phi_{1}\right)$, $3,74 \times 10^{17}\left(\Phi_{2}\right)$ и $5,6 \times 10^{17}\left(\Phi_{3}\right)$ ион $/ \mathrm{cm}^{2}$. Значения энергии ионов выбирались так, чтобы обеспечить примерно одинаковые расчетные профили их распределения [1] без учета распыления. Для приведения в равновесное состояние образцы подвергались термическому отжигу в вакууме $\left(6,6 \times 10^{-3}\right.$ Па) через $100{ }^{\circ} \mathrm{C}$ в диапазоне температур 773-1373 К (500-1100 ㄷ) с выдержкой каждого образца в течение 1 часа.

Идентификация структуры приповерхностных слоев проводилась по рентгенограммам, полученным с использованием узкого пучка монохроматизированного CuKa-излучения, направленного под скользящим $\left(6^{0}\right)$ углом к поверхности образца [2]. При образовании текстурированных фаз для уточнения результатов проводились дополнительные съемки при углах падения 3,9 и $15^{\circ}$. Время экспозиции при каждой съемке составило от 15 до 30 часов.

Экспериментальные результаты и их обсуждение

Имплантация азота в вольфрам. При внедрении ионов азота на рентгенограммах вольфрама появляется отчетливый набор рефлексов от текстурированной со следами поликристалла фазы, которая представляет собой нитрид вольфрама W2N с плотноупакованной ГЦК-структурой. Рентгенограммы показывают вид возникающих отражений при различных углах съемки. Их расплывчатость свидетельствует о степени разупорядоченности возникающей фазы. В текстурированном состоянии она возникает уже при дозах $1,87 \times 10^{17} \mathrm{~cm}^{2}$ и при увеличении дозы до $5,6 \times 10^{17} \mathrm{~cm}^{2}$ переходит в поликристаллическое состояние. Увеличение дозы имплантации приводит к изменению состояния появляющегося нитрида вольфрама от текстуры к поликристаллу.

Необходимо отметить, что после ионной имплантации на разных образцах получались на первый взгляд неоднозначные результаты. Дело в том, что исследуемые образцы вырезались сначала в виде дисков, которые затем разрезали на прямоугольники в произвольных направлениях. В случае образования фаз в поликристаллическом состоянии это не имеет существенного значения. Однако при образовании текстурированных фаз даже при использовании всего набора используемых углов падения рентгеновского пучка на образец рефлексы от них далеко не всегда могут попасть на регистрирующую пленку. При этом может сложиться ложное представление об отсутствии процесса образования фаз. В данной работе использовались образцы, разрезанные как в «ориентированных» направлениях, когда удавалось зарегистрировать воз- 
никающие рефлексы, так и в «неориентированных», где рефлексы не появлялись. При образовании наряду с текстурированной фазой хотя бы незначительного ее количества в поликристаллическом состоянии появлялась возможность более точного определения параметров решетки фазы.

После имплантации ионов азота в образцы вольфрама был проведен отжиг в интервале температур 773-1273 К (500-1000 $\left.{ }^{\circ} \mathrm{C}\right)$.

Отжиг привел к сужению отражений на рентгенограммах, что свидетельствует об упорядочении структуры и укрупнении частиц возникающей фазы. Наряду с этим отжиг при температурах, превышающих $900^{\circ} \mathrm{C}$, ведет дополнительно к образованию фазы $\mathrm{WO}_{3}$ моноклинной структуры, которая возникает в результате частичного окисления поверхности образца в атмосфере остаточных газов печи [3-4]. Можно отметить, что различные металлы после ионной имплантации по-разному ведут себя по отношению к остаточным газам при отжиге. Это зависит как от вида металла, так и от типа используемых ионов. Так, например, молибден проявляет большую склонность при отжиге связываться с углеродом, образуя карбид молибдена. В то же время образования

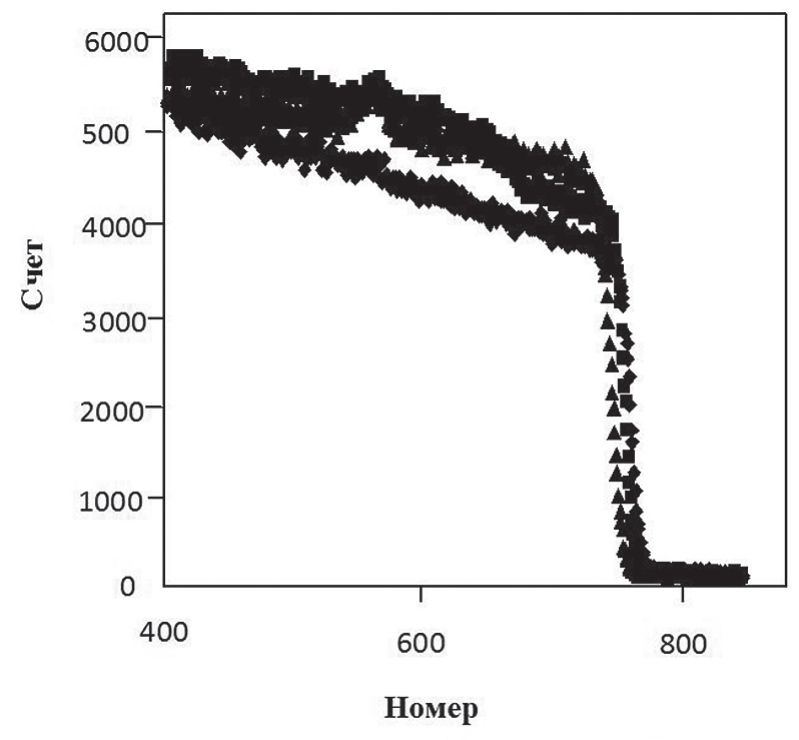

- исходный; - $1,87 \times 10^{17} \mathrm{~cm}^{-2} ; \boldsymbol{\Delta}-3,74 \times 10^{17} \mathrm{~cm}^{-2}$.

Рис. 1. Спектры обратного рассеяния протонов от поверхности вольфрама, имплантированного ионами азота

Имплантация кислорода в вольфрам. При внедрении ионов кислорода уже при дозе $1,87 \times 10^{17} \mathrm{~cm}^{2}$ на рентгенограммах возникают отражения от текстурированной со следами поликристалла фазы с ГЦК-структурой, которая, однако, не переходит в поликристаллическое состояние с увеличением окислов при отжиге ионно-имплантированного молибдена замечено не было [5]. По литературным данным $[6,7]$, среди известных нитридов единственной фазой, имеющей плотноупакованную структуру, является $\mathrm{W}_{2} \mathrm{~N}$. По этой причине, по-видимому, имплантация ионов азота приводит к образованию лишь фазы W $\mathrm{N}_{2}$ с ГЦК-решеткой, хотя при использованных наборах больших доз следовало бы ожидать также появления фазы WN с более высоким содержанием азота $[3,4]$.

На рисунке 1 представлены дозовые зависимости спектров резерфордовского обратного рассеяния для образцов вольфрама, имплантированного ионами азота. Результаты анализа приводят к тому, что при внедрении ионов азота в вольфрам концентрация азота в имплантированных слоях достигает определенного уровня, при превышении которого наблюдается процесс вытеснения его в соседние области с меньшей концентрацией. После имплантации максимум распределения при дозах $\Phi_{1}$ и $\Phi_{2}$ оказался в 2,6 раза глубже по сравнению с расчетным значением проективного пробега [1]. На рисунке 2 приведены зависимости относительного количества имплантированных ионов азота по глубине мишени.

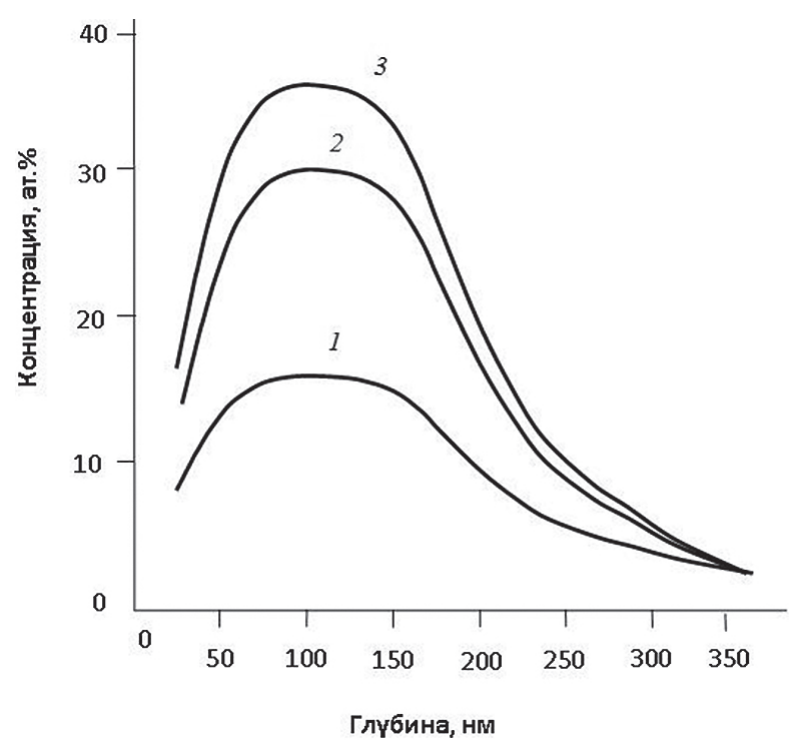

Рис. 2. Распределение по глубине азота в вольфраме при дозах: $1-1,87 \times 10^{17} \mathrm{~cm}^{2} ; 2-3,74 \times 10^{17} \mathrm{~cm}^{2}$; $3-5,6 \times 10^{17} \mathrm{~cm}^{2}$

дозы. Параметр решетки этой фазы, рассчитанный по слабым линиям ее поликристаллической составляющей, составил 0,4155 нм.

Послеимплантационный отжиг образцов вольфрама, имплантированных ионами кислорода, особых изменений в наблюдаемую картину не вносит 
вплоть до $1173 \mathrm{~K}\left(900^{\circ} \mathrm{C}\right)$. При достижении этой температуры на рентгенограммах появляется дополнительный набор линий от поликристаллической фазы $\mathrm{WO}_{3}$, но не моноклинной, как в случае имплантации азота, а гексагональной структуры. Последующий отжиг при 1273 К $\left(1000^{\circ} \mathrm{C}\right)$ приводит к распаду фазы $\mathrm{WO}_{3}$ и появлению вместо нее поликристаллического карбида вольфрама $\gamma$ - $\mathrm{W}_{2} \mathrm{C}$ гексагональной структуры. ГЦК-фаза, возникшая при имплантации, в процессе отжигов сохраняется. Отжиг при $1373 \mathrm{~K}\left(1100^{\circ} \mathrm{C}\right)$ ведет к исчезновению на рентгенограммах отражений от наблюдаемых фаз. При имплантации кислорода в вольфрам, на наш взгляд, получились интересные результаты. В этом случае образуется фаза с плотноупакованной ГЦК-структурой, близкая по структуре и параметрам к $\mathrm{W}_{2} \mathrm{~N}$. Вместе с тем процессы фазообразований в образцах, имплантированных азотом и кислородом, отличаются как по дозовой зависимости, так и по поведению при отжиге. При имплантации кислорода фаза появляется только в текстурированном состоянии и сохраняется в таком виде при отжиге.

Как было указано выше, при имплантации азота нами обнаружено появление оксида вольфрама $\mathrm{WO}_{3}$ моноклинной структуры при $1173 \mathrm{~K}\left(900^{\circ} \mathrm{C}\right)$. А теперь в случае имплантации кислорода в вольфрам образуется фаза с аналогичным стехиометрическим составом, но другой структуры - гексагональной. Другой

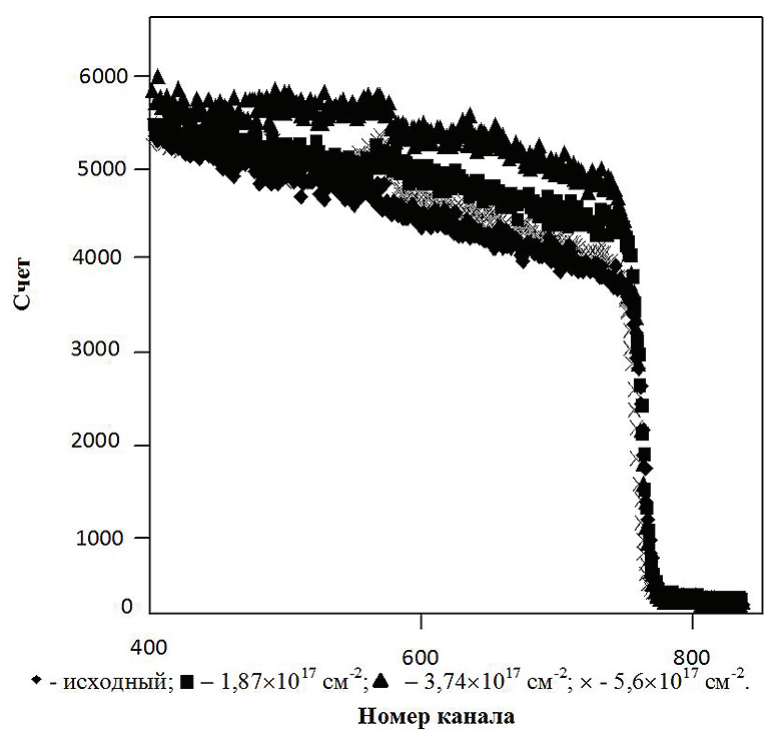

Рис. 3. Спектры обратного рассеяния протонов от поверхности вольфрама, имплантированного ионами кислорода

Сопоставляя полученные в данном разделе результаты с экспериментальными данными других авторов по имплантации вольфрама ионами кислорода, можно отметить интересные с точки зрения фазообразования полученные ими оксиды вольфрама. Так, в работе [8] особенностью является то, что в случае легирования кислородом возникающий оксид $\mathrm{WO}_{3}$ распадается при отжиге при 1273 К $\left(1000^{\circ} \mathrm{C}\right)$, тогда как в случае азота эта фаза не распадается. Следовательно, есть все основания предположить, что возникающая при имплантации вольфрама ионами кислорода фаза представляет собой оксид вольфрама $\mathrm{W}_{2} \mathrm{O}$, в которой атомы азота заменены атомами кислорода [3-4]. По литературным данным, система W-O характеризуется наличием оксидов $\mathrm{WO}_{2}, \mathrm{~W}_{18} \mathrm{O}_{49} \mathrm{~W}_{20} \mathrm{O}_{58}$, $\mathrm{WO}_{3}$ и т.д., среди которых обнаруженная нами структура отсутствует.

На рисунке 3 представлены дозовые зависимости спектров резерфордовского обратного рассеяния для образцов вольфрама, имплантированного ионами кислорода. Профили распределения кислорода в вольфраме при различных дозах аналогичны для случая азота, имплантированного в вольфрам. Результаты экспериментальных данных приводят к тому, что при имплантации ионов кислорода в вольфрам концентрация кислорода в имплантированных слоях достигает определенного уровня, при превышении которого наблюдается процесс вытеснения его в области с меньшей концентрацией. На рисунке 4 приведены зависимости относительного количества имплантированных ионов кислорода по глубине мишени.

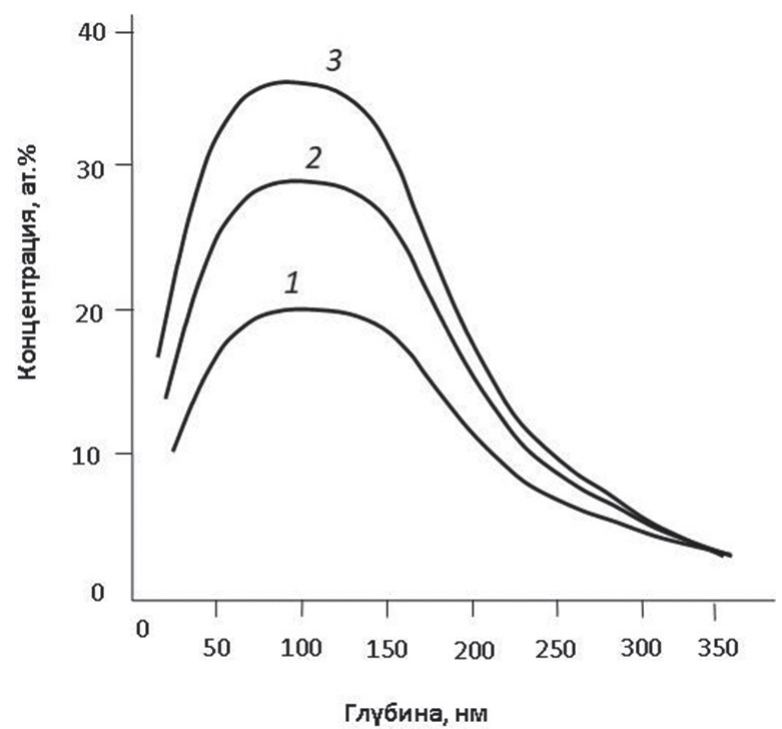

Рис. 4. Распределение по глубине кислорода в вольфраме при дозах:

$1-1,87 \times 10^{17} \mathrm{~cm}^{-2} ; 2-3,74 \times 10^{17} \mathrm{~cm}^{-2} ; 3-5,6 \times 10^{17} \mathrm{~cm}^{-2}$

легирование ионов кислорода в вольфрам проводили в интервале доз $10^{17-}-10^{18}$ ион $/ \mathrm{cm}^{2}$ с энергией $\mathrm{E}=100$ кэВ в вакууме $4 \times 10^{-5}$ Па. Исходные образцы вольфрама вырезали по плоскостям (110) и (111). Соответствующие отжиги проведены в диапазоне 873-1673 К. 
Электронографические исследования образцов вольфрама, легированного ионами кислорода с дозой $10^{17}-10^{18}$ ион/см², показали, что поверхностный слой всех образцов оказался аморфным до послеимплантационного отжига. Послеимплантационный отжиг в интервале температур 873-1073 К приводит к образованию фазы, значения межплоскостных расстояний которой, определенных из рентгенограмм, не совпадают со значениями межплоскостных расстояний для известных фаз в системе W-O [9]. Идентификация этой фазы была проведена на основании сравнения справочных и измеренных межплоскостных расстояний соединения $\mathrm{Mo}_{2} \mathrm{O}_{3}$.

На основании изоструктурности Мо и W полученное авторами соединение при температуре отжига 1073 К идентифицировали как триоксид дивольфрама. При температуре 1573 К это соединение начинает распадаться, и дальнейшее увеличение температуры отжига до 1673 К восстанавливает структуру чистого вольфрама. В данной работе интерес вызывает тот факт, что при дозе $1 \times 10^{18}$ ион/см² имплантация кислорода в вольфрам аморфизует ионно-легированный слой.

Имплантация фосфора в вольфрам. Имплантация фосфора в образцы вольфрама приводит к образованию и появлению на рентгенограммах рефлексов от поликристаллической фазы $\mathrm{WC}_{1-x}$ с параметрами решетки $a=0,42355$ нм, которые появляются за счет углерода, осажденного на поверхность образцов при имплантации внедрения его методом отдачи. Последующий изохронный отжиг не внес существенных изменений в наблюдаемую картину вплоть до $1073 \mathrm{~K}\left(800^{\circ} \mathrm{C}\right)$. Отжиг при температурах $1073-1173$ К (800-900ㄷ) ведет к исчезновению фазы $\mathrm{WC}_{1-\mathrm{x}}$ и появлению фосфида вольфрама $\mathrm{WP}_{2} \mathrm{c}$ op-

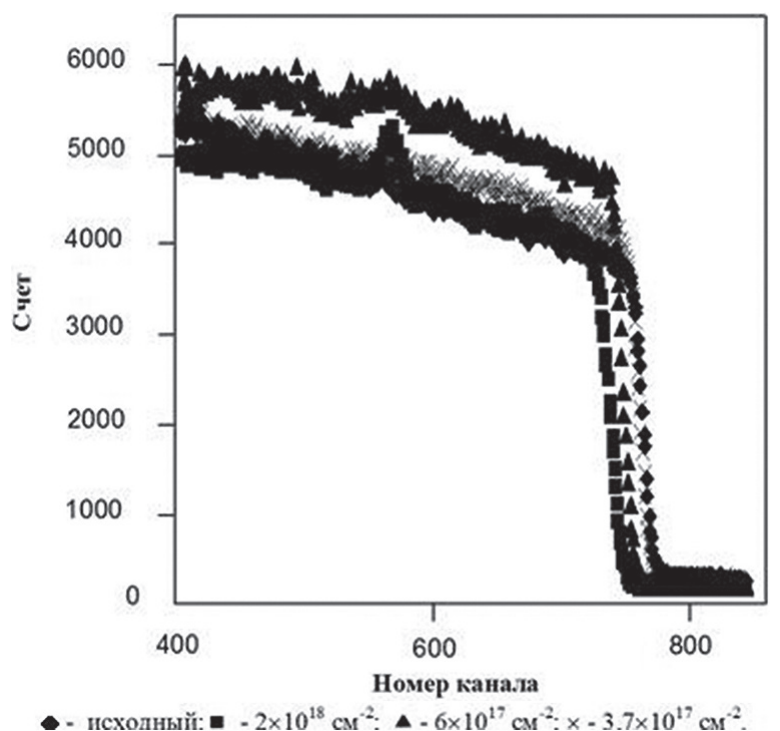

Рис. 5. Спектры обратного рассеяния протонов от поверхности вольфрама, имплантированного ионами фосфора торомбической решеткой и параметрами решетки $a=0,3165$ нм, $b=1,1159$ нм и $c=0,4973$ нм [9].

По литературным данным, диаграмма состояния W-P не построена. Однако, согласно [6], система $\mathrm{W}$-P характеризуется наличием двух соединений WP и $\mathrm{WP}_{2}$. Соединение $\mathrm{WP}_{2}$ было получено ранее из чистых элементов при 973-1173 К, который при нагреве (873 К) разлагается и при температуре 1173-1273 К переходит в WP. Соединение $\mathrm{WP}_{2}$ существует в двух модификациях $-\alpha-\mathrm{WP}_{2}$ и $\beta-\mathrm{WP}_{2}$.

Анализ полученных результатов приводит к тому, что при имплантации фосфора в вольфрам эффект появления новой фазы не был зарегистрирован. Очевидно, причиной этому может служить тот факт, что после имплантации не был зарегистрирован переход кристаллической решетки вольфрама в аморфное состояние, что является необходимым условием наблюдения и появления фазы. Второй причиной может быть то, что достигнутая доза имплантации оказалась недостаточной для такого вида фазовых переходов.

На рисунке 5 представлены спектры резерфордовского обратного рассеяния для образцов вольфрама, имплантированного ионами фосфора. В отличие от спектров РОР образцов вольфрама, имплантированного ионами азота и кислорода, концентрация атомов фосфора с увеличением дозы имплантации непрерывно повышается. Здесь наблюдается тенденция к насыщению, связанная с эффектами распыления. Концентрационные профили распределения фосфора в вольфраме при различных дозах $\left(\Phi_{1}, \Phi_{2}\right.$ и $\left.\Phi_{3}\right)$ показывают, что максимум распределения глубже по сравнению с расчетным в 2,9 раза [1]. На рисунке 6 приведены зависимости относительного количества имплантированных ионов азота по глубине мишени.

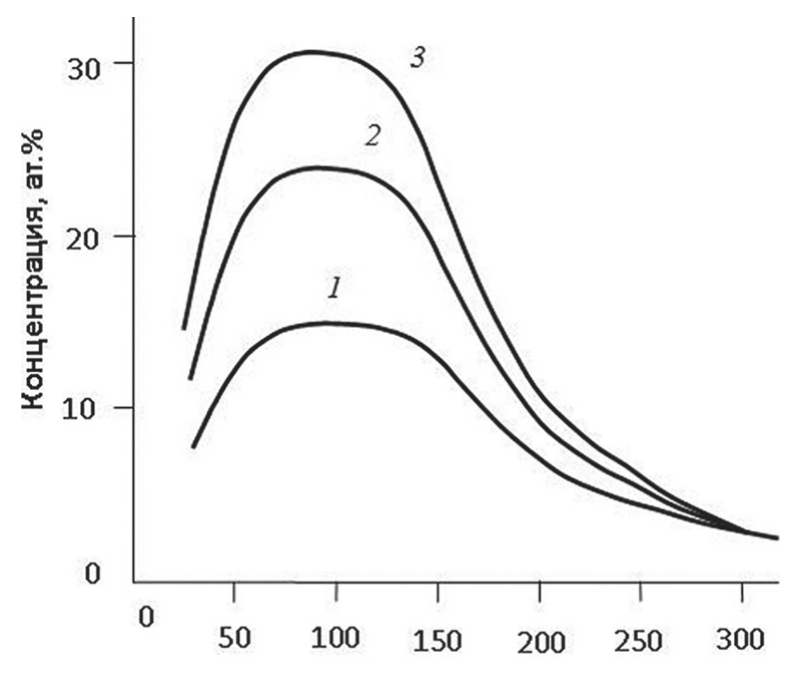

Глубина, нм

Рис. 6. Распределение по глубине фосфора в вольфраме при дозах:

$1-3,74 \times 10^{17} \mathrm{~cm}^{-2} ; 2-6 \times 10^{17} \mathrm{~cm}^{-2} ; 3-2 \times 10^{17} \mathrm{cM}^{-2}$ 
Работы по структурно-фазовым превращениям в вольфраме, имплантированном ионами фосфора, в литературе практически отсутствуют. Поэтому данные результатов этого раздела сопоставимы с экспериментальными результатами аналогичных работ по ионной имплантации образцов других переходных металлов, например молибдена, поскольку молибден родственен вольфраму и его фосфиды представляют практический интерес.

Из известных в литературе работ по ионной имплантации фосфора в массивные образцы переходных металлов отметим работу авторов [10] по имплантации молибдена ионами фосфора. Согласно работе [10], при внедрении ионов фосфора в молибден при дозе $5 \times 10^{17} \mathrm{~cm}^{-2}$ и энергии $\mathrm{E}=100$ кэВ замечено возникновение рефлексов от монокристаллического молибдена, характеризующее деформацию модифицированных слоев и появление рефлексов от текстурированной фазы карбида молибдена $\mathrm{Mo}_{2} \mathrm{C}$. Отжиг образцов привел к восстановлению формы рефлексов от монокристаллического молибдена. Последующий отжиг при 1173 К привел к возникновению набора рефлексов от фосфида молибдена $\mathrm{Mo}_{3} \mathrm{P}$ с тетрагональной структурой в текстурированном состоянии. Дальнейший отжиг при 1473 К привел к полному его распаду. Появление карбида молибдена $\mathrm{Mo}_{2} \mathrm{C}$ связано с имплантацией атомов углерода методом отдачи из атмосферы остаточных газов ускорителя. Синтез фосфида молибдена Мо $_{3}$ Р в ионно-имплантированных слоях, как и в нашем случае, происходит лишь при определенной температуре. При этом порог образования определяется температурой перехода метастабильного твердого раствора в соответствующем химическом соединении, стехиометрический состав которого отражает, по мнению авторов, среднюю концентрацию внедренной примеси в имплантированных слоях, оставшуюся при их нагреве до температур фазового перехода.

Образование фаз внедрения $\mathrm{W}_{2} \mathrm{~N}, \mathrm{~W}_{2} \mathrm{O}$ и $\mathrm{W}_{2} \mathrm{P}$ при ионной имплантации является результатом локализации сдвиговой деформации в условиях ускоренного массопереноса. В условиях высокодозной ионной имплантации формируются высоконеравновесные пересыщенные твердые растворы, а также высокодефектные структурно-неравновесные состояния с высокой кривизной кристаллической решетки.

\section{Заключение}

На основании экспериментальных данных (рис. 2, 4, 6) установлена максимальная глубина проникновения ионов азота, кислорода и фосфора в вольфрамовую мишень. Эта глубина составляет порядка 250-350 нм, что не противоречит экспериментальным данным, полученным другими авторами. Согласно работе В.Е. Панина [11], утверждающей, что возможен эстафетный механизм массопереноса атомов в направлении приложенного внешнего давления, можно оценить диаметр канала, по которому проходят имплантированные ионы. Размер этот не может превышать величину межатомных расстояний (0,35 нм) в мишени вольфрама.

По данным распределений имплантированных ионов по глубине мишени, расчет величины локального давления составил как минимум $700 \mathrm{MПа,} \mathrm{что} \mathrm{со-}$ ответствует пределу текучести материала мишени.

Следовательно, под давлением ионного пучка возникает пластическая деформация материала мишени, а значит, кривизна кристаллической решетки. Согласно В.Е. Панину [12], кривизна кристаллической решетки является движущей силой направленного массопереноса.

В зонах кривизны решетки возникают сильно возбужденные неравновесные и новые разрешенные структурные состояния, имеющие собственную полосу энергетических состояний в электронно-энергетическом спектре [13]. В результате возникают новые структурные состояния или новые фазы.

Фазы внедрения образовались вследствие локальной деформации приповерхностного слоя за счет границы упругих модулей между поверхностным слоем, имеющим высокую концентрацию имплантированных ионов, и основным материалом. При известных дозах имплантации начинается генерация дислокаций, процесс накопления которых приводит к дальнейшему росту деформаций. За счет коллективных эффектов взаимодействия деформация решетки достигает своего максимального значения. Такое состояние кристалла, после которого в условиях существенной деформации образуется упругая дисторсия, связанная с возникновением кривизны решетки. Это ведет к развитию ротационной неустойчивости, приводящей к формированию фаз внедрения.

\section{Библиографический список}

1. Кумахов М.А., Муравлев В.Л., Аверьянов Е.Г., Симонов В.А., Хавкин Л.П. Проективные пробеги и разбросы пробегов для 20 кэВ $\leq \mathrm{E} \leq 1000$ кэВ. М., 1974.

2. Абдрафиков А.П., Каздаев Х.Р., Баядилов Е.М., Кадыржанов К.К. Фотометрирование рентгенограмм моду- лированным световым пучком // Изв. АН КазССР. Сер. : Физ.-мат. 1984. № 6.

3. Абылкалыкова Р.Б., Каздаев Х.Р., Скаков М.К. Ионнолучевой синтез соединений в вольфраме // Вестник КазНУ. Сер. : Физ. 2004. № 1 (16). 
4. Abylkalykova L., Kveglis H. Kazdaev Regularities of Formation of the Ordered Structures in Refractory Metals at Ion Implantation. Journal of Siberian Federal Univercity. Engineering \& Technologies. 2011. № 3.

5. Kazdaev Kh., Akchulakov M.T., Bayadilov E.M. Synthesis of Compounds in Molybdenum during Ion Implantation Combined with Thermal and Pulsed Electron Annealing // Phys. Research. 1990. V. 13.

6. Диаграммы состояния двойных металлических систем / справочник под ред. академика Н.П. Лякишева. М., 2001. Кн. 1, т. 3.

7. Барабаш О.М., Коваль Ю.Н. Структура и свойства металлов и сплавов / справочник. Киев, 1986.

8. Деканосидзе Р.Н., Диасамидзе Э.М., Кутелия Э.Р. и др. Структурные изменения в монокристаллах вольфрама при имплантации ионов кислорода // Поверхность. ФХМ. 1988. № 10.
9. JCPDS-International Centre for Diffraction Data. PDF-2 Data Base (Sets 1-51 plus 70-89).

10. Каздаев Х.Р., Акчулаков М.Т., Баядилов Е.М. Синтез соединений в молибдене, имплантированном ионами кремния, фосфора и серы // Поверхность. ФХМ. 1990. № 8 .

11. Панин В.Е., Гриняев Ю.В. Елсукова Т.Ф., Иванчин А.Г. Структурные уровни деформации твердых тел // Изв. вузов. Физика. 1982. № 6.

12. Панин В.Е., Панин А.В., Елсукова Т.Ф., Попкова Ю.Ф. Фундаментальная роль кривизны кристаллической структуры в пластичности и прочности твердых тел // Физ. мезомех. 2014. Т. 17. № 6.

13. Панин В.Е., Егорушкин В.Е. Солитоны кривизны как обобщенные волновые структурные носители пластической деформации и разрушения // Физ. мезомех. 2013. T. 16. № 3. 